\title{
Alceu Penna e suas permanências
}

Alceu Penna and his permanences

Alceu Penna - Inventando a moda do Brasil

Curadoria: Luiza Penna Andrade. Museu da Moda de Belo Horizonte, Belo Horizonte, Minas Gerais, Brasil. De 11 de dezembro de 2019 a 7 de junho de 2020. 
Gabriela Ordones Penna ${ }^{1}$

ORCID: http://orcid.org/0000-0002-1239-6650

É possível arriscar que grande parte dos eventos descritos a seguir tenha tido a contribuição de Thereza de Paula Penna Guatimozin, porque no ciclo infindável da vida, no qual nem sempre se sabe o que veio primeiro, o começo ou o fim (se é que existe tal coisa), essa mulher mudou um pouco a história das artes visuais no Brasil. Ah, sim! Provavelmente, estamos falando aqui de alguém famoso, um artista - o leitor já deve estar confabulando a essa altura. Não era. Seu nome não foi capa de livro ou mesmo constou das chamadas de exposições ou de espetáculos de prestígio. Isto, no entanto, nada significa. Thereza dedicou grande parte da sua vida a preservar a memória de um notável artista gráfico, seu irmão Alceu de Paula Penna. Uma dupla, sem dúvida. Mais do que irmãos, parceiros profissionais. Thereza acompanhou os momentos áureos de Alceu na revista $O$ Cruzeiro, quando ele fazia sucesso desenhando as primeiras pin-ups totalmente made in Brazil, assinando a seção de moda mais acompanhada da época e comparecendo a desfiles internacionais de maisons como Givenchy. Comum? Não para meados do século XX, quando os jornais e as revistas brasileiros compravam fotografias de agências de notícias internacionais e as estampavam sem um pingo de adequação com a nossa cultura e os nossos costumes.

Uma breve pausa na narrativa. Belo Horizonte, no ano de 2015, presenciou a exposição comemorativa do centenário de Alceu Penna no então Centro de Referência da Moda - CRModa, intitulada Alceu Penna é 100!. Passados nove anos do falecimento de Thereza, o trabalho desse mineiro de Curvelo não fora esquecido, pelo contrário, nunca tinha sido tão lembrado. A obra de uma carreira toda sobreviveu durante décadas em um país que se recusa a dar valor à sua cultura e ao seu passado ou ainda àqueles que, mesmo não estando nos palcos, foram fundamentais para a história brasileira. Esse trabalho, contrariando todas as expectativas, deu frutos e foi afastado do ostracismo e esquecimento. E isso tem tudo a ver com Thereza. Foi pelo seu trabalho constante ao longo dos anos em receber pesquisadores, jornalistas, estudantes e interessados no apartamento que dividiu com o irmão no bairro do Flamengo no Rio de Janeiro, mostrando croquis, compartilhando histórias e experiências que esse legado sobreviveu.

A iniciativa de fazer uma exposição, que partiu da família Penna, compelida a comemorar a data importante, reuniu uma equipe diversa: as arquitetas Luiza Penna Andrade, curadora da mostra, e Gabriela Brasil iniciaram o projeto com o Centro de Referência de Moda por meio de edital público. Logo depois, convidaram as pesquisadoras especialistas

\footnotetext{
Doutora em Arte e Cultura Visual pela Universidade Federal de Goiás (UFG). Mestre em Moda, Cultura e Arte pelo Centro Universitário Senac São Paulo. Professora nos cursos de Comunicação, Design e Moda do Centro Universitário UNA (MG). Pesquisadora da obra do artista gráfico Alceu Penna, de quem é sobrinha-neta, e autora do livro Vamos, garotas! Alceu Penna, moda, corpo e emancipação feminina (AnnaBlume, 2010). E-mail: gabriela.penna@prof.una.br. Lattes: http://lattes.cnpq. br/2988623244462323
} 
na obra do artista Gabriela Penna e Maria Claudia Bonadio, além da artista plástica Mariângela Penna e da designer de moda Raquel Penna. Foi um momento em que o Museu da Moda - Mumo estava começando a traçar sua história na capital mineira, a princípio como Centro de Referência - CRModa e, mais tarde, em 2016, oficialmente como museu.

A exposição comemorativa do centenário do artista exibiu alguns dos seus croquis originais e objetos pessoais de trabalho (como estojos de tintas e pastel), além de peças de vestuário e alguns acessórios desenhados por Alceu nunca mostrados ao público, como chapéus, bolsas e luvas, oriundos do seu acervo pessoal no Rio de Janeiro e também de familiares, especialmente das sobrinhas, para as quais ele desenhava bastante ${ }^{2}$. Um dos destaques da mostra foi o vestido de casamento usado na cerimônia religiosa de Maria Carmen Penna, irmã de Alceu, com Natércio Pereira, da década de 1950, desenhado pelo artista e confeccionado em renda francesa.

Após o término do evento, alguns familiares quiseram doar parte desses objetos ${ }^{3}$. Assim, esse conjunto de itens, posteriormente, retornou para a guarda do museu parceiro da instituição, o Museu Histórico Abílio Barreto - MHAB, onde recebeu cuidados de conservação coordenados por Susan Barnes. Nascia, da exposição comemorativa do centenário, a coleção de Alceu Penna do Museu da Moda de Belo Horizonte.

Outra pausa, agora para avançar até fim do ano de 2019. Na mesma cidade, no mesmo museu, outra exposição do artista gráfico Alceu Penna aconteceu: Alceu Penna - Inventando a moda do Brasil, com curadoria de Luiza Penna Andrade. O que mudou nos quatro anos que separaram essas duas exposições? A princípio, o evento de 2019 teve uma proposta similar à do centenário, ou seja, exibir a coleção do artista abrigada no museu e manter viva a sua memória. No entanto, apresentaram diferenças significativas.

Primeiramente, a mostra foi dividida em três seções. A que compôs o segundo andar do museu foi dedicada aos objetos da coleção de Penna do Mumo ${ }^{4}$ (figuras 1 e 2), tais como recortes e revistas, catálogos de exposições, roupas desenhadas por Alceu Penna para as sobrinhas e as irmãs ${ }^{5}$ e acessórios, como chapéus, bolsas e luvas ${ }^{6}$ - a grande maioria já exibida no evento do centenário, em 2015. Aqui, a diferença significativa foi a ausência do vestido de

\footnotetext{
2 PENNA, Gabriela Ordones. Produções de sentidos em um arquivo pessoal: as ilustrações de figurinos de Alceu Penna para o show Brazil Export (1972). 2016. 110 f. Tese (Doutorado em Arte e Cultura Visual) - Universidade Federal de Goiás, Goiânia, 2016

ANDRADE, Luiza Penna. Informação oral obtida via telefone. Belo Horizonte, 12 de janeiro de 2020.

${ }^{4}$ A coleção de Penna é composta por 72 peças, entre roupas, acessórios e itens diversos, como material de desenho, catálogos e croquis. Informação cedida via e-mail pelo museólogo do Mumo Victor Pinheiro Louvisi. Belo Horizonte, 9 de janeiro de 2020.

Datadas das décadas de 1940 a 1970, as roupas que compõem a coleção são diversas, como tailleurs de lã, vestidos de veludo, vestidos de festa de seda, um minivestido azul-turquesa com animal print, além de outras preciosidades, como o vestido em laise da cerimônia do casamento civil de Maria Carmen, irmã de Alceu Penna, realizado em 1952.

Os principais acessórios da coleção Penna do Mumo são os chapéus, com destaque para um causal, de palha, que pertenceu a Alceu Penna, além dos casquetes, turbantes de musselina, luvas de seda e couro e bolsas de palha e couro.
} 
casamento de Maria Carmen, doado à Casa da Marquesa de Santos - Museu da Moda Brasileira ${ }^{7}$, no Rio de Janeiro, onde se encontra o acervo pessoal de Penna ${ }^{8}$.

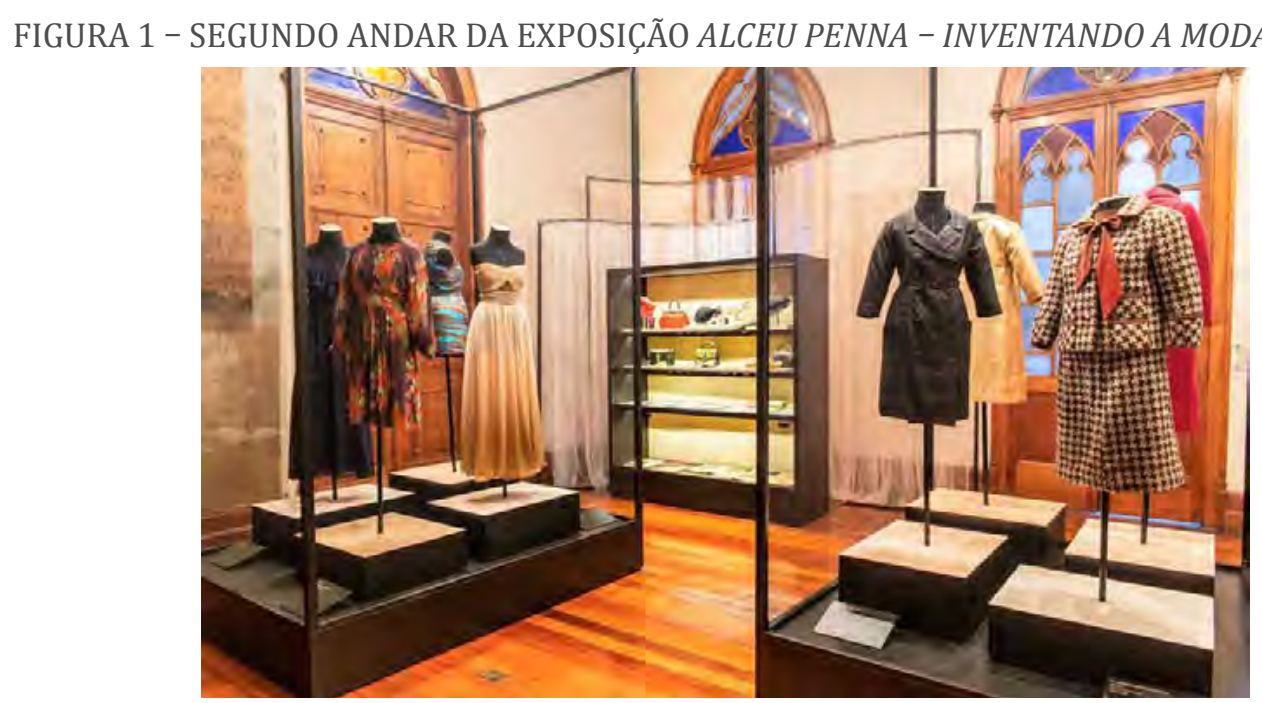

FONTE: Museu da Moda, Belo Horizonte, 2019. Foto: MUMO.

FIGURA 2 - ACESSÓRIOS DA COLEÇÃO DE ALCEU PENNA, TAIS COMO BOLSAS DE COURO E PALHA, CHAPÉUS, CASQUETES E LUVAS. EXPOSIÇÃO ALCEU PENNA - INVENTANDO A MODA DO BRASIL

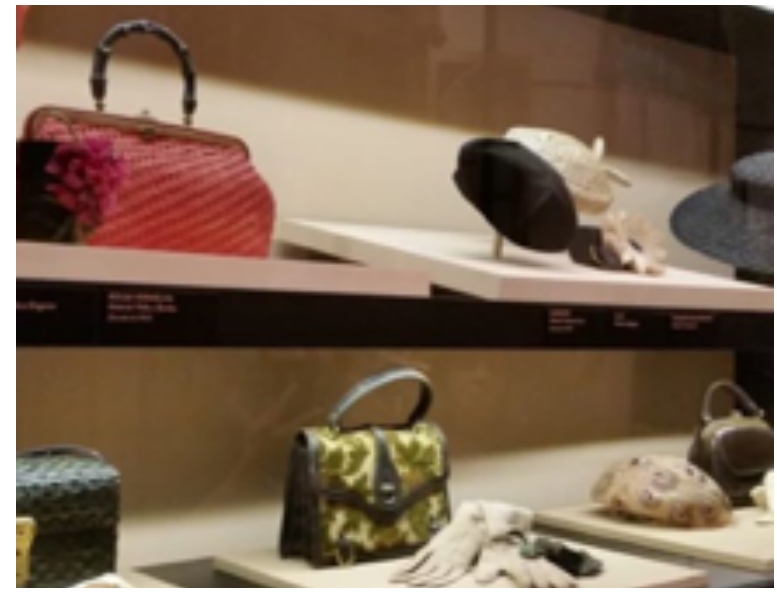

FONTE: Museu da Moda, Belo Horizonte, 2019. Foto: MUMO.

\footnotetext{
7 ANDRADE, Luiza Penna. Informação oral cedida via telefone. Belo Horizonte, 10 de fevereiro de 2020.

${ }^{8}$ A doação ao Museu da Moda Brasileira, no Rio de Janeiro, foi concretizada em 2015. Para saber mais: PENNA, Gabriela Ordones. Produções de sentidos em um arquivo pessoal: as ilustrações de figurinos de Alceu Penna para o show Brazil Export (1972). 2016. $110 \mathrm{f}$. Tese (Doutorado em Arte e Cultura Visual) - Universidade Federal de Goiás, Goiânia, 2016.
} 
Outra grande distinção foi quanto à qualidade do projeto expográfico, assinado pelo arquiteto Alexandre Rousset em parceria com a Voltz Design, que criou a identidade visual, do convite oficial à tipografia, em que predominavam os grafismos e o tom rosa suave. Ainda no segundo andar, foi montado um painel do tempo ilustrado (figura 3) com os eventos mais importantes da carreira de Penna. 0 seu formato sinuoso lembrava as formas da icônica calçada da praia de Copacabana, lugar-cenário das Garotas do Alceu.

\section{FIGURA 3 - PAINEL ILUSTRADO DA CARREIRA DE ALCEU PENNA. EXPOSIÇÃO ALCEU PENNA - INVENTANDO A MODA DO BRASIL}

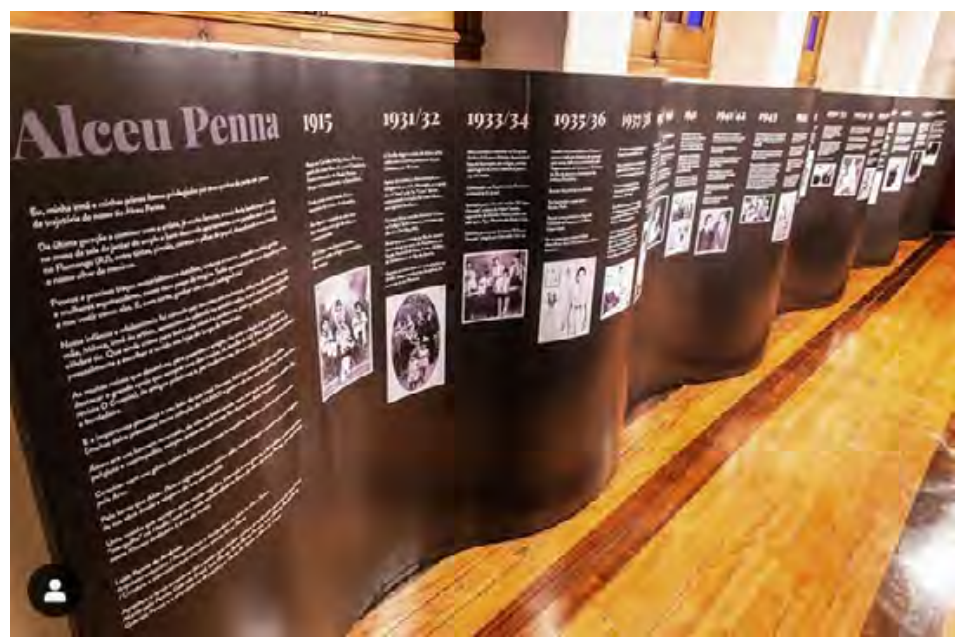

FONTE: Museu da Moda, Belo Horizonte, 2019. Foto: MUMO.

FIGURAS 4 E 5 - À ESQUERDA, TIPOGRAFIA CRIADA PELA VOLTZ DESIGN; À DIREITA, O CONVITE OFICIAL DA EXPOSIÇÃO ALCEU PENNA - INVENTANDO A MODA DO BRASIL
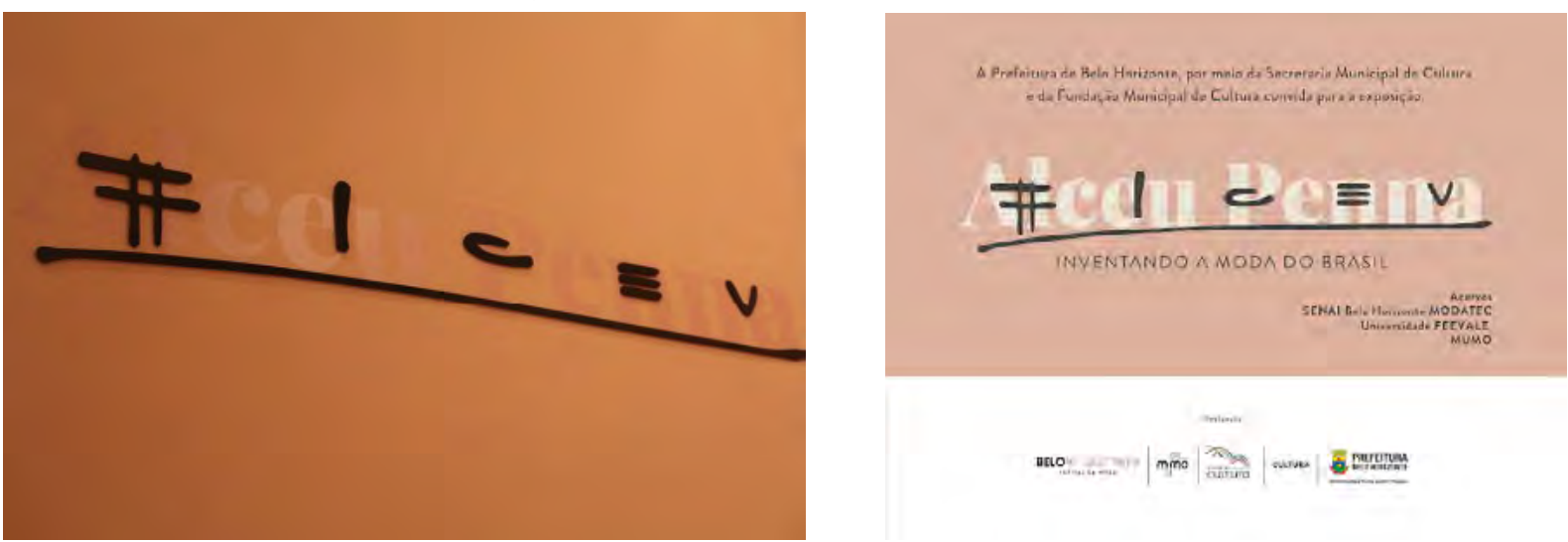

FONTE: Museu da Moda, Belo Horizonte, 2019. Fotos: Gabriela Penna.

As roupas e os acessórios também tiveram uma melhoria substancial na sua exposição. Os looks foram exibidos em caixas grandes cobertas por um fino tule que os protegia, mas permitia observar os detalhes e as texturas sem os reflexos indesejados de uma caixa 
de vidro, por exemplo. As placas metálicas informativas em tom ônix, padronizadas, quase desapareciam no fundo escuro, sem interferir na observação de cada objeto.

0 tule, aliás, foi um recurso visual chave presente em todo o projeto da exposição. O glamour da era de ouro do Rio de Janeiro em meados do século XX e a inocência de tempos de otimismo da política desenvolvimentista de JK foram revelados nas cores suaves e femininas e também no tule, que lembrava as saias bufantes em várias camadas das moças da sociedade nos anos 1950, sendo elas mineiras, paulistas ou cariocas. Afinal, 0 Cruzeiro circulava no Brasil todo e Alceu Penna era uma espécie de farol fashion das novidades.

0 recurso do tule continuou presente no primeiro andar da exposição, onde o visitante se deparava com um manequim giratório vestindo uma blusa de veludo bordada, pertencente à sobrinha Mara Penna, adornado por uma saia volumosa, confeccionada em tule (figura 6). Ao fundo, uma cortina do mesmo tule rosado mostrava-se presente. Ao lado do manequim, um par de sapatos e um chapéu de festa com plumas. Segundo Luiza Penna Andrade, curadora da mostra, a ideia da saia em tule foi elaborada em conjunto com a sobrinha-neta e designer de moda Rachel ${ }^{9}$.

Ficou evidente, nessa montagem, a inspiração na exposição da Maison Christian Dior no Victoria and Albert Museum, no início de 2019, que usou recurso semelhante - manequins com saias de tule volumosas e paleta de cores que iam do rosa-claro e bege ao branco-perolado, marca registrada da maison. Essa conexão fez sentido, principalmente, pela relevância que a Dior teve no período mais ativo de Penna à frente dos editoriais de moda de $O$ Cruzeiro e $A$ Cigarra.

\section{FIGURA 6 - NA PRINCIPAL VITRINA, MANEQUIM GIRATÓRIO COM BLUSA BORDADA ASSINADA POR PENNA E ACESSÓRIOS. EXPOSIÇÃO ALCEU PENNA - INVENTANDO A MODA DO BRASIL}

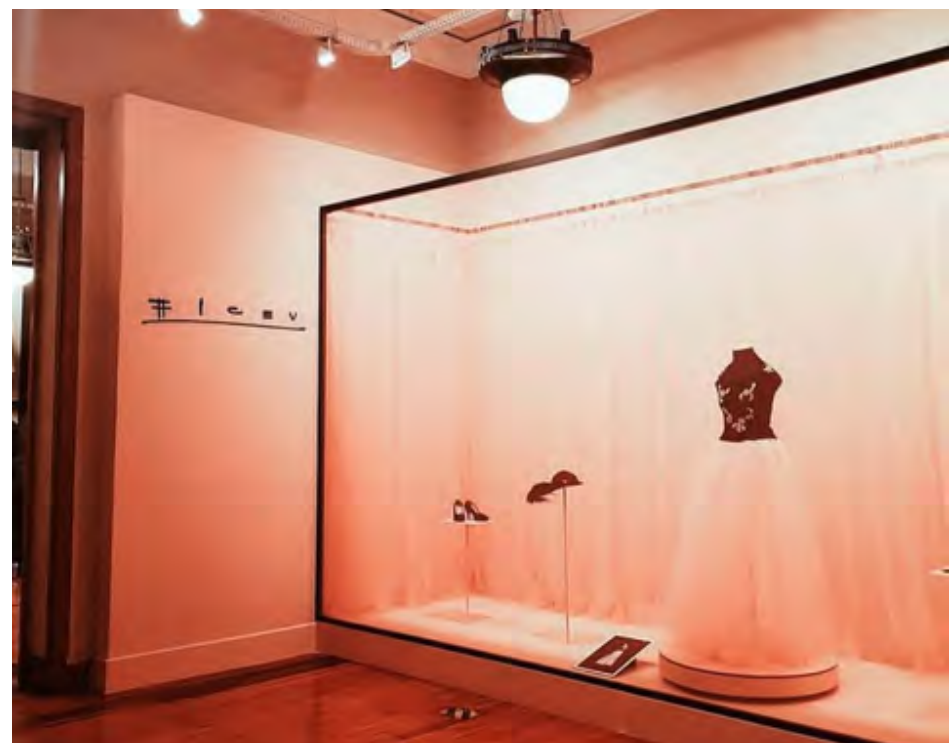

FONTE: Museu da Moda, Belo Horizonte, 2019. Foto: MUMO.

\footnotetext{
${ }^{9}$ ANDRADE, Luiza Penna. Informação escrita cedida por e-mail. Belo Horizonte, 10 de fevereiro de 2020.
} 
Outro grande diferencial foi que a exposição de 2019 não abarcou apenas peças desenhadas por Alceu e croquis originais, como a do centenário. Houve, também, a adição do acervo de outra exposição, Alceu Penna é show - Figurinos e fantasias -, originalmente realizada no Espaço Cultural Feevale, em 2016. Essa mostra teve a curadoria e a idealização da profa. Ana Hoffmann, com o apoio de Luiza Penna Andrade, que, com os alunos da instituição, criou releituras de croquis selecionados do artista. Outro acervo também incorporado à exposição de 2019 foi Alceu Penna decodificado, um projeto de releituras realizado por designers e modelistas do Senai Modatec de Belo Horizonte exposto no 24ํㅡㅁ Minas Trend Preview, coordenado pelo estilista Ronaldo Fraga ${ }^{10}$.

Observando a exposição, é perceptível que o projeto da Feevale privilegiou releituras de figurinos para cassinos e fantasias de Carnaval, especialmente os das décadas de 1930 e 1940. Destaque para o figurino inspirado no bolero, fielmente reproduzido com bolas brancas em alto relevo e o enorme chapéu lilás (figura 7). Houve um cuidado para que o conjunto todo fosse reproduzido, incluindo os acessórios, a exemplo de um croqui que lembrava uma deusa mitológica e seu capacete-armadura. 0 Carnaval também esteve presente nos figurinos inspirados em arlequins e pierrôs, marcantes na produção de Alceu Penna para as folias de Momo.

\section{FIGURA 7 - MOSTRA DA EXPOSIÇÃO ALCEU PENNA É SHOW - FIGURINOS E FANTASIAS DA FEEVALE. EXPOSIÇÃO ALCEU PENNA - INVENTANDO A MODA DO BRASIL}

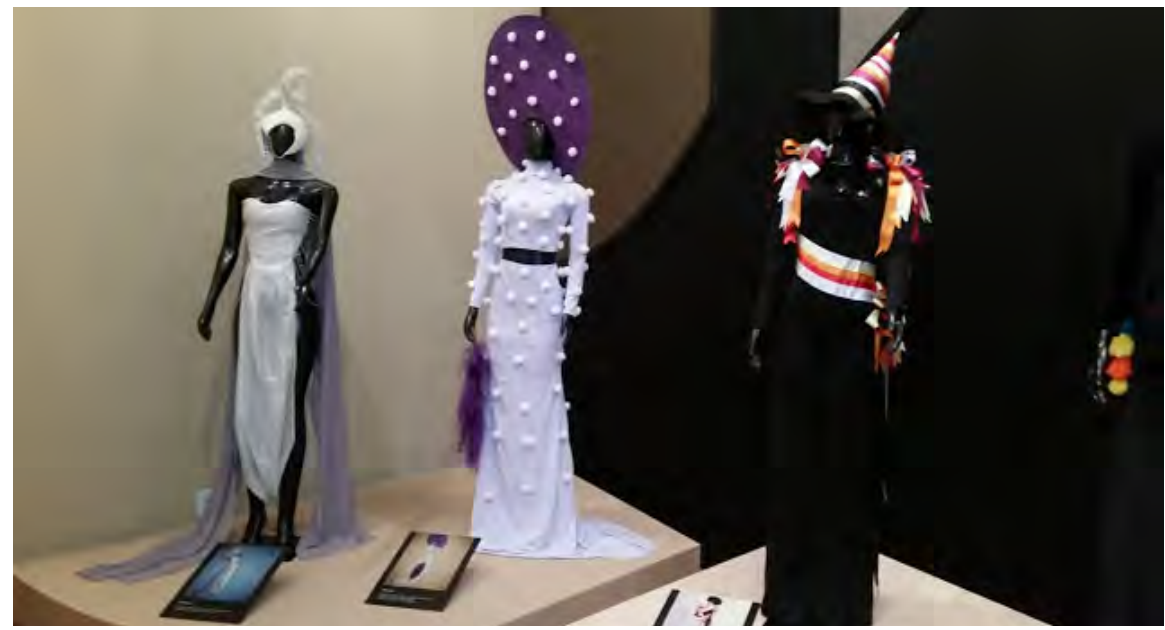

FONTE: Museu da Moda, Belo Horizonte, 2019. Foto: Gabriela Penna.

\footnotetext{
${ }^{10}$ Aqui, é necessário fazer um pequeno desvio para mencionar uma conexão com outra exposição que aconteceu no Senac São Paulo, em 2006, O Brasil na ponta do lápis - Alceu Penna, modas e figurinos, com curadoria da profa. Maria Claudia Bonadio, pesquisa histórica da sobrinha-neta e então aluna do mestrado Gabriela Penna e coordenação de modelagem de Daniela Figueiras. Essa exposição foi um marco no estudo do trabalho de Alceu no âmbito acadêmico da Moda no Brasil, uma vez que, apesar dos trabalhos acadêmicos de grande relevância e eventos que o homenagearam, foi a primeira vez que a obra de Alceu Penna contou com um projeto exclusivo em uma universidade, originalmente intitulado Projeto Figurino, que uniu tanto a graduação em Moda e quanto o programa de mestrado em Moda, Cultura e Arte do Senac São Paulo. O escritor Ruy Castro assinou o texto de abertura, destacando o pioneirismo e a importância de Alceu Penna para as artes visuais no país.
} 
A seção do Senai Modatec também mostrou uma proposta de releitura, porém com gêneros misturados, que iam de fantasias, como um macaquinho listrado em preto e branco e um enorme laço vermelho, a roupas mais casuais, típicas das páginas de moda de $O$ Cruzeiro, como os vestidos em godê característicos dos anos 1950 e 1960 e os conjuntos estampados que remetiam às décadas de 1960 e 1970 (figura 8).

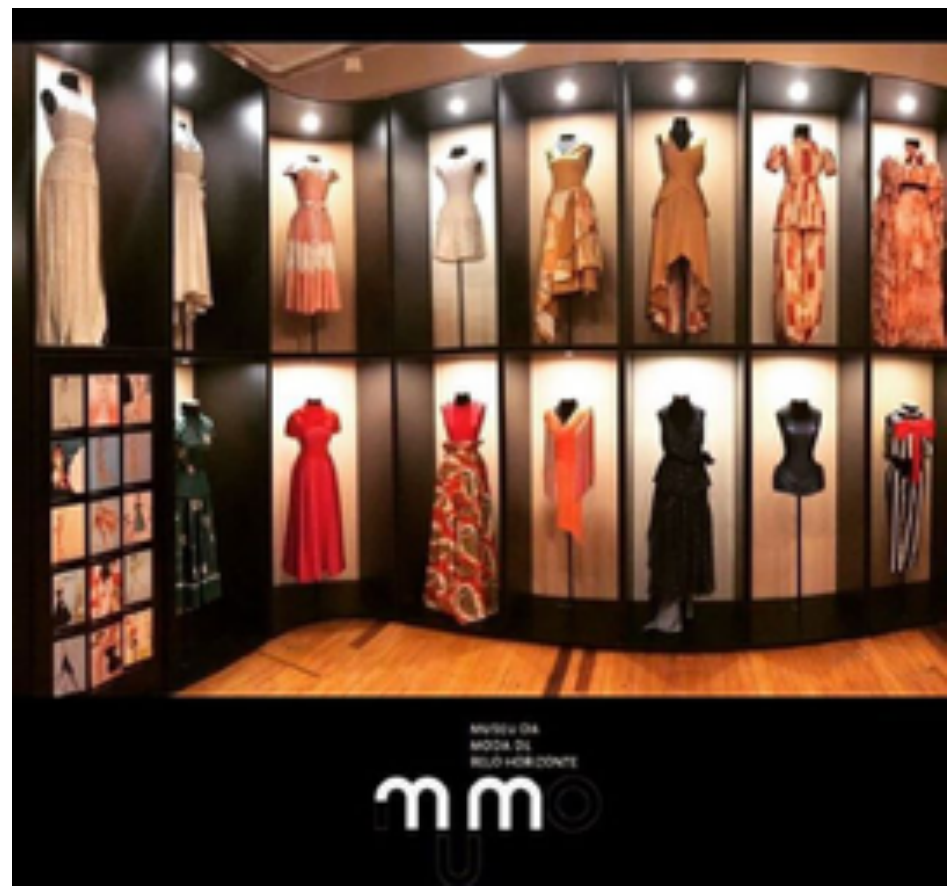

FONTE: Museu da Moda, Belo Horizonte, 2019. Foto: MUMO.

A confecção impecável das peças em ambas as mostras e o cuidado em expor os desenhos próximos das roupas impressionaram. Apesar desse zelo, faltaram as informações históricas dos desenhos nos quais se basearam as releituras. É compreensível, muitas vezes, que determinados croquis não tenham datas exatas identificadas ou mesmo uma finalidade conhecida. Figurino ou fantasia de Carnaval? Essa dificuldade já foi levantada por pesquisadores que trabalham com a obra do artista gráfico em estudos acadêmicos e artigos científicos. Mesmo que o objetivo dos projetos que originaram essas mostras não fosse exclusivamente esse, seria interessante um maior aprofundamento histórico, uma amarração daqueles conjuntos de peças em um discurso que produzisse sentidos para além da já reconhecida importância do trabalho e do legado de Alceu Penna.

É importante ressaltar ainda a relevância dos projetos da Feevale e do Senai Modatec especialmente no espaço expositivo de Alceu Penna de 2019, pois são provas elementares de como o passado e o presente podem e devem estar em contínua sintonia ao motivar e 
engajar alunos no estudo histórico do vestuário, abordando a obra de Penna, parte da história da moda brasileira. Além disso, ao propor releituras, esses dois projetos aproximaram o aluno dos desafios impostos do croqui à materialização da roupa, algo que deve ser sempre valorizado. Foi sobre isso que a profa. Ana Hoffmann discursou no evento de abertura da exposição Alceu Penna - Inventando a moda do Brasil, em 2019, enfatizando os estudos de materiais que tiveram que ser feitos no processo de interpretação dos croquis de Penna.

Em última análise, a exposição de 2019 marcou a doação definitiva de parte do acervo pessoal de Alceu Penna para o Mumo como coleção de destaque, assim como o início de um projeto maior. Ela foi um divisor de águas, pois marca uma mudança aguardada pela comunidade - a de ser um museu com suas plenas funções e capacidades -, revelada no começo do projeto da construção de uma reserva técnica própria para receber o seu acervo.

Esse sempre foi um grande obstáculo à instituição que, com recursos limitados e desafios impostos pelas modificações na estrutura tombada, ficava refém da guarda do museu parceiro Abílio Barreto. Não há dúvidas de que, com a passagem de CRModa para museu, era preciso que se resolvesse com urgência esse embaraço, duramente criticado pela comunidade. No entanto, parecia que ainda faltavam recursos e investimentos para que tal mudança fosse feita. Em quatro anos, muita coisa mudou a fim de que uma mostra com esse porte pudesse acontecer. A gestora do museu, Maria Carolina Ladeira Dias, ressaltou em entrevista o trabalho árduo realizado até o momento de abertura da exposição, que contou com uma equipe de museólogos, estagiários, técnicos e profissionais, que orquestrou tudo a contento, driblando aspectos legais da doação e administrativos. Ela reforçou que o sentimento que permeou os trabalhos até o dia da inauguração da exposição era de perpetuação do legado de um artista que acreditava em uma moda brasileira criativa. ${ }^{11}$.

É visível que a mostra de 2019 teve mais recursos do que a do centenário, de 2015, que contou com a cessão do espaço, o apoio de divulgação e o suporte da equipe da instituição. A exposição de 2019, além disso tudo, ganhou investimentos substanciais e o apoio da Fundação Municipal de Cultura para que pudessem ser realizadas as melhorias na expografia e a contratação de profissionais especializados, entre outras necessidades ${ }^{12}$. Foi um reconhecimento duplo: do Mumo, como espaço museológico da moda em Belo Horizonte, e de Alceu Penna, como importante parte da história mineira. Como diz um velho ditado popular, o bom filho a casa torna.

\footnotetext{
${ }^{11}$ DIAS, Maria Carolina. Depoimento cedido via telefone. Belo Horizonte, 14 de janeiro de 2020. ${ }^{12}$ ANDRADE, Luiza Penna. Informação oral cedida via telefone. Belo Horizonte, 10 de fevereiro de 2020.
} 


\section{Referências}

PENNA, Gabriela Ordones. Produções de sentidos em um arquivo pessoal: as ilustrações de figurinos de Alceu Penna para o show Brazil Export (1972). 2016. 110 f. Tese (Doutorado em Arte e Cultura Visual) - Universidade Federal de Goiás, Goiânia, 2016.

\section{Exposições}

CENTRO REFERÊNCIA DA MODA - CRMODA. Alceu Penna é 100! Belo Horizonte: Centro de Referência da Moda, 2015. (Edição comemorativa do 100a aniversário de Alceu Penna. Curadoria de Luiza Andrade Penna)

SENAC SÃO PAULO. O Brasil na ponta do lápis: Alceu Penna, modas e figurinos. São Paulo: Senac São Paulo, 2016. (Exposição com curadoria de Maria Claudia Bonadio)

VICTORIA AND ALBERT MUSEUM. Christian Dior, designer of dreams. Londres: Victoria and Albert Museum, 2019. (Exposição com curadoria de Oriole Cullen)

MINAS TREND PREVIEW. Alceu Penna decodificado. Belo Horizonte: 03 de abril, 2019. (Exposição das releituras feitas pelos alunos do Senai Modatec apresentada no $24^{\circ}$ Minas Trend Preview, com coordenação de Ronaldo Fraga)

FEEVALE. Alceu Penna é show - Figurinos e fantasias. Belo Horizonte: Feevale, 2016. (Exposição com curadoria de Ana Hoffmann)

\section{Agradecimentos}

A Luiza Penna Andrade, curadora da exposição Alceu Penna - Inventando a moda no Brasil e atuante na preservação da memória de Alceu Penna pelo apoio a escrita dessa resenha; a Victor Louvisi, museólogo do MUMO, pelas valiosas informações e recepção sempre cuidadosa; a Maria Carolina Ladeira, gestora do MUMO, pela dedicação notável ao projeto; e a Maria Claudia Bonadio pela contribuição incessante na perpetuação desse legado. 